Logos Universality Mentality Education Novelty, Section: Social Sciences

ISSN: $2284-5747$ (print), ISSN: $2284-5747$

(electronic)

Covered in: CEEOL, Index Copernicus, Ideas

RePeC, EconPapers, Socionet

\title{
BRIDGE TO THE UNCONSCIOUS: THE COMBINED USE OF KALFFIAN SANDPLAY AND VOCAL PSYCHOTHERAPIES
}

\author{
Sana LOUE \\ Logos Universality Mentality Education Novelty, Section: \\ Social Sciences, 2014, Year III, Issue 1, pp: 85-93 \\ Published by: \\ Lumen Publishing House \\ On behalf of: \\ Lumen Research Center in Social and Humanistic Sciences
}




\title{
Bridge to the Unconscious: The Combined use of Kalffian Sandplay and Vocal Psychotherapies
}

\section{Sana LOUE ${ }^{1}$}

\begin{abstract}
Sandplay therapy involves the use of water, sand, and miniature toys and symbols. These materials are used in a mediating process that allows material from the conscious and the unconscious to be organized in a new way to effectuate psychological, emotional, and spiritual bealing. Sandplay is both nonverbal and nondirective, providing the client with a safe therapeutic space that facilitates process at a pre-verbal, nonrational level. Vocal psychotherapy also deals with unconscious material, such as regression in service to the self and dissociation. In contrast to sandplay therapy, vocal psychotherapy uses the breath, singing, and music in the voice through techniques such as vocal holding and free associative singing. The pairing of sandplay therapy and vocal psychotherapy is a pairing of two nondirective forms of therapy, one of which is nonverbal and the other vocal, but with or without words. The use of vocal psychotherapy together with sandplay therapy may enhance and reinforce the insights gained by the client.
\end{abstract}

\section{Keywords:}

Nonverbal communication; Psychotherapy; Sandplay therapy; Vocal psychotherapy;

\footnotetext{
${ }^{1}$ Professor, Bioethics, Psychiatry, Epidemiology and Biostatistics, Global Health and Vice Dean for Faculty Development and Diversity, Case Western Reserve University School of medicine, Cleveland, Ohio USA, sana.loue@case.edu, 01-216-368-3743.
}

LOUE, S. (2014). Bridge to the Unconscious: The Combined use of Kalffian Sandplay and Vocal Psychotherapies. Logos Universality Mentality Education Novelty, Section: Social Sciemces, Year III, Issue 1, 2014, pp. 85-93 


\section{Introduction}

Bridging and integrating one's inner and outer worlds is key to achieving individual wholeness. In the context of a therapeutic relationship, it is important to identify the modality or modalities that are potentially most beneficial to the client in furthering this process.

Both Kalffian sandplay and vocal psychotherapy facilitate this mediation between the client's conscious and unconscious worlds. They operate at a preverbal, nonrational level to effectuate emotional, spiritual, and psychological healing, Each approach individually provides the client with a unique path towards enhanced selfawareness and, combined together, can enhance the client's insights.

The use of each of these modalities, however, requires that the therapist receive advanced training in order to utilize the method safely with client. Both sandplay therapy and vocal psychotherapy are specialized modalities of therapy. They would not be welcome by or advisable for every client.

\section{Kalffian Sandplay: Theory and Method}

\subsection{The development of the theory}

The technique of Kalffian sandplay was developed by Dora Kalff, a Swiss therapist. She derived this method from an integration of Margaret Lowenfeld's Worldtechnik, Carl Jung's work, and her understandings of Zen Buddhism. Lowenfeld believed that play reflects the child's inner reality, which was to be received unconditionally by the trustworthy therapist (Domenico, 1999). As a therapist, Lowenfeld created a protected space to which a child could return and in which a child could freely communicate through the use of his or her senses and bodily action and play (Hutton, 2004).

Carl Jung theorized that the Self is comprised of both conscious and unconscious components of the psyche (Jung, 1967). If all of the newborn infant's needs are met, this totality of the person is kept safely within the Self of the mother during the first year following birth (Neumann, 1973). Kalff reasoned that, after this first year, the child separates from the Self of the mother. Then, during the child's second year and into the third, the child's center of his or her own Self stabilizes in the child's unconscious. The child's unconscious begins to manifest in symbols. According to Kalff, this manifestation of the Self, this inner order, this pattern of wholeness, is the most important moment in the development of the personality" ... and seems to guarantee the consolidation of the personality (Kalff, 2003, p. 6).

Over time, however, we have allowed the ego to gain primacy over the Self (Weinrib, 1983). The ego is rooted in the unconscious and, as a result, is vulnerable to emotionally charged complexes. The more that one tries to ignore a complex, the more the complex will overtake the control of the ego. Sandplay therapy seeks 
to "revitalize the ego-that is, for the ego to relinquish its illusory dominance and to reestablish a connection and continuing relationship between consciousness and unconscious" (Weinrib, 1983, p. 20).

In sandplay therapy, the client uses symbols as a means of expression, transferring what he or she is inwardly experiencing to the outer world of the sandtray, using the miniature symbols. Carl Jung explained that "it is of considerable practical importance that the symbols aiming at wholeness should be correctly understood by the doctor ... They are répresentations collective which facilitate the much-needed union of conscious and unconscious. This union cannot be accomplished either intellectually or in a purely practical sense ..." (Jung, 1963, p. 191).

The symbols that the client uses are symbols for archetypes; archetypes are universal patterns of experience and meaning. Jung believed that each person inherits transpersonal, universal aspects of the personality; these are experience so the collective, rather than of the singular individual. These images, which Jung clustered into archetypes, appear across cultures in dreams, myths, fairy tales, and stories (Jung, 1916, 1929). Archetypes have both negative and positive aspects to them.

Weinrib (1983, p. 37) has explained that the "primary thrust of sandplay is the reestablishment of access to the feminine elements of the psyche in both men and women, elements that have been repressed in Western Judeo-Christian culture." If a child is inadequately parented, the child's image of the mother becomes injured and is no longer adequate to provide nurture to the child. As a result, the child's perception becomes distorted and the maturation of his or her personality is hampered. The first such injury occurs at the separation of the child from the mother and an increase in the child's own consciousness. This is a normal separation and is not problematic is there is adequate mothering. However, if there "is early maternal deprivation that produces serious injury to the archetypal image of the mother," the child will have a negative and destructive image of the mother archetype. Through sandplay therapy, the client, whether an adult or a child, can reimage this negative archetypal image as one that is more positive. This re-imaging will permit the individual to move forward with his or her growth (Weinrib, 1983, pp. 33-34).

\subsection{Kalffian sandplay: The method}

Kalffian sandplay uses a standard size rectangular sandtray that measures $72.39 \mathrm{~cm} \times 49.022 \mathrm{~cm} \times 7.62 \mathrm{~cm}$. The bottom and sides of the tray are painted blue and the tray is filled about halfway with sand. The sandtray is ideally waterproofed so that the client can moisten the sand with water as needed. Many sandplay therapists maintain two separate sandtrays, one for dry sand and the second for wet sand. The miniature symbols that are available for the client to use are openly displayed on shelves and in drawers so that the client can access them easily. They 
can be categorized into various groupings: buildings; trees and other plants; wild animals; domestic animals; fantasy animals, people; modes of transportation; gates, walls and bridges; fantasy and folkloric people; and other materials such as string and paper (Thomson, 1981). The sandtray gives the client a "free and protected space," where he or she can be with acceptance and without judgment (Weinrib, 1983).

Many times, the client may make the tray in silence. The therapist does not interpret the tray to the client at the time that it is made (Kalff, 2003). Instead, the therapist might ask the client if he or she would like to say something about the tray, or how the client feels looking at the tray that he or she has made (Weinrib, 1983). Information that the therapist gleans from the sandplay will only be used in an indirect way with the client. The therapist will use the client's comments to frame a hypothesis and will evaluate what the client has done in the context of Jungian symbology and archetype. The therapist's evaluation and interpretations remain constantly subject to the therapist's re-examination because they have not been presented to the client for verification, modification, or refutation (Weinrib, 1983).

\section{Vocal Psychotherapy}

\subsection{Theory}

Vocal psychotherapy was developed by Diane Austin, a New York-based music psychotherapist. The technique rests on the knowledge that the voice is a versatile musical instrument (Jourdain, 1997), that singing is a neuromuscular activity, and that muscular patterns are associated with psychological patterns and emotional response (Newham, 1998). By using one's voice, the client is able to express all of his or her feelings (Austin, 2008).

Like sandplay therapy, vocal psychotherapy recognizes the importance of the bond between mother and infant. That bonding occurs in response to touch, eye contact, and sound (Miller, 1981). The infant will tune in to the sound of his or her mother's voice. If all goes well, the mother will be attuned to the various sounds that the infant makes in its efforts to communicate with her and the infant will feel secure in his or her mother's responses (Miller, 1987).

The infant will begin to make babbling, singing sounds at about three or four months of age. These singing sounds are reminiscent of the child's soothing mother (Winnicott, 1965). As the baby grows older, he or she will begin to vocalize sounds, using the lips and tongue, and will also learn to recognize his or her mother's distinctive voice (Moses, 1954). As Austin notes, "The vocal interaction in speech and song between mother and child is critical to the child's developing sense of self. This sound connection reflects the emotional and psychological relationship between the mother and her child" (Austin, 2008, pp. 22-23). 
This pleasurable stage does not, however, last forever. Instead, as the individual goes through life, he or she will self-censor so as not to reveal all of his or her feelings. The individual may block his or her emotions in an effort to selfprotect; this, in turn, may lead to constricted breathing and a more limited vocal range. Liberating the voice can help to liberate the breath and allow the individual to become more in touch with his or her feelings.

Vocal psychotherapy, like sandplay, draws from the theories of Carl Jung. Music can serve as a vehicle to mediate between the unconscious and the conscious (Austin, 1996). Indeed, music may allow the client to reach deep archetypal material that would otherwise be inaccessible (McGuire \& Hull, 1977). The qualities of a client's music may provide insights into an existing complex. For example, the rhythm, melody, pitch, and harmony of a client's vocalizations may communicate fear or judgment or betrayal, suggesting that there is an underlying conflict requiring attention. Austin has explained how this can occur:

Music allows the image and the feelings associated with the complex to be channeled into a concrete form, for example, 'the needy part'. The ego can then relate to a previously unknown aspect of the unconscious and begin to integrate it into one's selfimage. The energy tied up with the dissociated part then becomes available for conscious use and the personality becomes more complete (Austin, 2008, p. 45).

\subsection{Vocal psychotherapy: Toning as connection}

Although vocal psychotherapy encompasses a variety of techniques, this article focuses on toning, which is perhaps one of the, if not the, most nondirective component of vocal psychotherapy. Toning has been described as "the conscious use of sustained vowel sounds for the purpose of restoring the body's balance. Sound vibrations free blocked energy and resonate with specific areas of the body to relieve emotional and physical stress and tension" (Austin, 2008, p. 29). Toning permits the client to connect with the therapist on both a sensory and a feeling level in a way that can feel safe. Toning can also be utilized to induce an altered state of consciousness and mediate contents from the personal and collective unconscious to the conscious mind" (Austin, 2008, p. 31). We can begin to see here how both sandplay therapy and vocal psychotherapy may mediate between and bridge the conscious and unconscious worlds, each emphasizing

\section{Transference, countertransference, cotransference and communication}

Transference occurs when someone, usually unconsciously, assigns to a current relationship feelings that actually derive from another relationship. For example, a therapist may remind a client of his overbearing mother and he may react to the therapist as if she were his mother. This is an example of negative 
transference because it involves the transference of negative emotions. The transference would be positive if the client had had a warm and nurturing relationship with his mother, and he reacted with positive emotions to the therapist as he would to his mother because she reminded him of her.

Countertransference is similar, but involves the conscious or unconscious "transfer" of feelings from the therapist to the client; the therapist's emotional response to the client actually stems from her earlier experience with someone else. Just as with transference, countertransference may be positive or negative. Sandplay therapy most frequently uses the term "cotransference" rather than transference and countertransference, in order to signify a

feeling with (co), rather than a feeling against (counter) ... [The term is used] to designate the therapeutic feeling relationship between therapist and patient. These inter-feelings seem to take place almost simultaneously, rather than sequentially as the composite term transference-countertransference suggests" (Bradway \& McCoard, 1997, p. 34).

A skillful understanding of the transference and countertransference that occurs between the therapist and the client can give the therapist significant insight into the client's situation. In essence, the cotransference becomes a means of communication.

Cotransference in sandplay may occur in any of three ways: directly onto the sandtray; onto the contents of the sandtray, which may include the sand and the symbols; and through the sandtray in the therapeutic relationship (Montecchi, 1993). Weinrib (1983) has suggested that the sand tray serves the function of a transitional object, that is, "an intermediate area of experiencing to which inner reality and external life both contribute" (Winnicott, 1975, p. 230). As the client separates from the therapist, the transference moves from the therapist to the sandtray.

A similar dynamic may occur with vocal psychotherapy. Transference and countertransference may occur through the voice, the music, the musical instruments, or directly between the therapist and the client (Austin, 2004).

\section{The integrative use of sandplay and vocal psychotherapies: A case example}

The sandtray and voice of a client during one session provides an example of how sandplay therapy and vocal psychotherapy can be integrated into a therapeutic session to facilitate client communication, both with the therapist and with him- or herself.

Figure 1 displays a photo of the sandtray that the client made during this session. Considerations of client confidentiality preclude a detailed discussion of the session contents. The client had encountered significant life challenges in the 
past, including a mental illness. After he made this sandtray, he explained that it depicted for him the new road that he was on. He felt that he was more in balance and feeling positive. He indicated that as he looked forward, he realized that he still had a lot of work to do and, as he got older, it seemed that scaling life's challenges was more difficult that $t$ had been when he was younger.

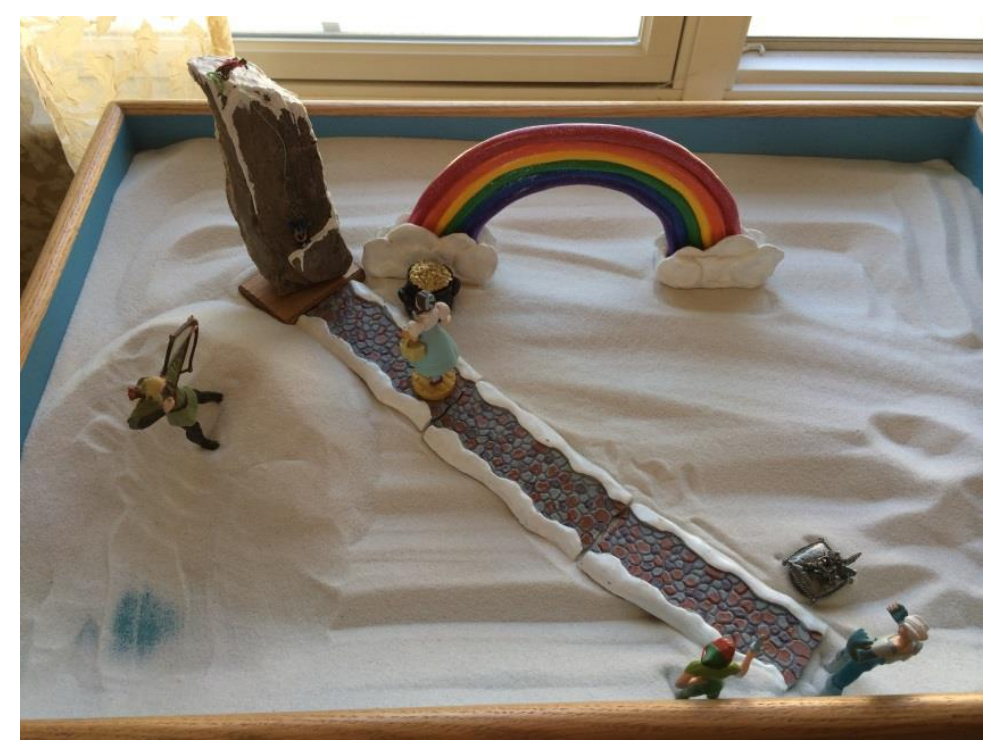

Fig. 1 - Client Sandplay

After the client had made his sandtray and spent some time speaking about it we moved to the piano. He asked that I find on the piano chords that he felt reflected what he feels like when he is trying to scale the mountain that he had placed in his sandtray. We alternated playing these chords, which were in a lower octave, with the chords that the client thought would reflect how it feels when he would finally reach the top of the mountain; these were higher chords. As I played the alternating chords, the client and I both toned those notes.

The client then explained what he had felt as he had voiced the notes. He had been to a social event the previous weekend. In the past, he would have felt uncomfortable among the many people who were there. On this occasion, however, he had made an effort to be social and to interact with others who were present. The client commented that the contrast between the lower notes-how it felt to be scaling the mountain - and the higher notes- how it felt to be on top of the mountain - helped him to realize how much he had been accomplishing. $\mathrm{He}$ said he had come to realize that "moving fast is not the same as going somewhere."

The use of both sandplay and vocal psychotherapy together helped this client in this session to become more aware of his tendency to do something, anything in an effort to "go somewhere" in life, even when there was no real 


\section{Logos Universality Mentality Education Novelty}

Section: Social Sciences

direction to the going. In essence, direction-less activity had provided him with a means to ignore and channel any anxiety that he might have been feeling, rather than working through the anxiety. Potentially, the client would be able to use this new insight as he works to develop healthier ways of dealing with anxiety.

\section{References}

Austin, D. (1993). Projection of parts of the self onto music and music instruments. In G.M. Rolla (Ed.), Your inner music. Wilmette, IL: Chiron.

Austin, D. (1996). The role of improvised music in psychodynamic music therapy with adults. Music Therapy, 14, 29-43.

Austin, D. (2008). The theory and practice of vocal psychotherapy: Songs of the self. London: Jessica Kingsley Publishers.

Austin, D. (2004). When words sing and music speaks: A qualitative study of in depth music psychotherapy with adults. Ann Arbor, MI: UMI Number 3110989.

Bradway, K., \& McCoard, B. (1997). Sandplay: Silent workshop of the psyche. New York: Routledge.

Domenico, G.S. (1999). The legacy of Margaret Lowenfeld: The Lowenfeld World Technique and Lowenfeld sandplay. Sandtray Network Journal. Available at http://www.gapt.org/pdf_files/ ARTICLES\%20VOL\% 201-9/0501\%20THE $\% 20 \quad$ LEGACY $\% 20$ OF $\% 20$ MARGARET $\% 20$

LOWENFELD-DEDOMENICO.pdf. Accessed September 13, 2013.

Hutton, D. (2004). Margaret Lowenfeld's "World Technique." Clinical Child Psychology and Psychiatry, 9, 605-612.

Jourdain, R. (1997). Music, the brain, and ecstasy. New York: Avon Books.

Jung, C.G. (1916). The psychology of the unconscious. The collected works of C.G. Jung, vol. 7. Bollingen Series. Princeton, NJ: Princeton University Press.

Jung, C.G. (1929). Problems of modern psychotherapy. . The collected works of C.G. Jung, vol. 16. Bollingen Series. Princeton, NJ: Princeton University Press.

Jung, C.G. (1963). Psychology and religion, general remarks on symbolism, vol. 11, collected works. New York: Pantheon Books, Inc.

Jung, C.G. (1967). Symbols of transformation, Vol. 5, collected works. New York: Pantheon Books, Inc.

Kalff, D.M. (2003). Sandplay: A psychotherapeutic approach to the psyche. Cloverdale, CA: Temenos Press.

McGuire, W., \& Hull, R.F.C. (1977). C.G. Jung speaking. Princeton, NJ: Princeton University Press.

Montecchi, F. (1993).Giocando con la sabbia: La psicoterapia con bambini e adolescenti et la sandplay therapy. Franco Angelli. Cited in M. Kalff. (2003). Sandplay: A pathway to the psyche. In D.M. Kalff, Sandplay: A psychotherapeutic approach to the psyche (pp. v-xvi). Cloverdale, CA: Temenos Press.

Miller, A. (1981). The drama of the gifted child. New York: Basic Books.

Miller, A. (1987). The drama of being a child. London: Virago Press. 
Moses, P.J. (1954). The voice of neurosis. New York: Grune \& Stratton.

Neumann, E. (1973). The child. New York: G.P. Putnam's Sons.

Newham, P. (1998). Therapentic voicework: Principles and practice for the use of singing as a therapy. London: Jessica Kingsley Publishers.

Thomson, C. (1981). Variations on a theme by Lowenfeld: Sandplay in focus. In C.G. Jung Institute of San Francisco. Sandplay studies: Origins, theory, and practice (pp. 5-20). Boston: Sigo Press.

Weinrib, E.K. (1983). Images of the self. Boston, MA: Sigo Press.

Winniccott, B. (1965). The maturational process and the facilitating environment. London: Hogarth Press.

Winnicott, B. (1975). Transitional objects and transitional phenomena. In Through pediatrics to psychoanalysis. New York: Basic Books.

LOUE, S. (2014). Bridge to the Unconscious: The Combined use of Kalffian Sandplay and Vocal Psychotherapies. Logos Universality Mentality Education Novelty, Section: Social Sciemces, Year III, Issue 1, 2014, pp. 85-93 